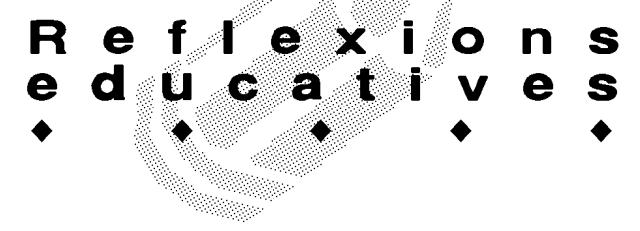

\title{
LA FLAUTA DOLÇA: UN INSTRUMENT PER ENSENYAR MÚSICA AL S. XXI
}

\author{
Josep Gustems Carnicer. Àrea de Didàctica de l'Expressió Musical. Universitat de Barcelona
}

\section{Introducció}

La flauta dolça és un instrument musical àmpliament conegut; possiblement sigui, a la llum de les xifres, l'instrument més universal, tant per la seva presència en l'espai com en el temps. També és un instrument usat des de fa diverses dècades a l'educació primària i secundària a molts països europeus, especialment entre els que tenen una educació musical fonamentada en la tradició metodològica Orff. Al nostre país fa anys que s'està estudiant a les escoles primàries, secundàries $\mathrm{i}$ de magisteri, amb criteris molt amplis. Paradoxalment, el coneixement d'aquest instrument tan comú és, sovint, molt parcial i, fins i tot, precari.

L'interès per l'ensenyament de la flauta dolça es remunta documentalment a 1535, amb La Fontegara, el primer tractat que es conserva destinat a l'ensenyament d'un instrument musical, i ja llavors l'escollit fou la flauta dolça. Des d'aquell moment les publicacions musicals i didàctiques referides a la flauta dolça han sigut pràcticament constants, i han posat de manifiest el gran interès per l'instrument des del s. XVI fins als nostres dies. Malgrat l'abundància de mètodes i publicacions que han caracteritzat la segona meitat del s. XX, aquesta no sempre s'ha vist prou acompanyada pel corresponent procés de validació de resultats i d'investigacions rigoroses. Així s'evidencia tant per l'escassa presència en biblioteques $(0,0086 \%$ del Catàleg Col-lectiu de les Biblioteques de Catalunya, 2001), com per tesis doctorals $(0,0016 \%$ de les catalogades fins al 2001, a tot l'àmbit internacional), com per presència en els tesaures (flauta dolça no consta en cap, i flauta només apareix en un d'ells). L'educació musical, desvinculada durant massa temps dels centres d'investigació, pateix un desfasament respecte a altres àrees de coneixement.

Les fonts documentals de flauta dolça són d'un àmbit geogràfic molt ampli, d'origen fonamentalment europeu fins al s. XVIII. Una anàlisi més rigorosa ens mostra diferents implicacions de cada país al llarg de la història: així, trobem que al $\mathrm{s}$. XVI Itàlia fou el país protagonista; al s. XVII s'hi afegiria França i al s. XVIII Anglaterra prendria el relleu. A la primera meitat del $\mathrm{s}$. XX seran de nou Anglaterra i posteriorment Alemanya les grans promotores de la difusió de la flauta dolça, mentre que a la segona meitat trobarem ja una àmplia incidència d'EUA, el Japó i d'altres països europeus com Holanda o Espanya. Aquests últims anys i per l'ús de les xarxes d'informació (internet...) s'han multiplicat, dispersat i disseminat les fonts.

Un dels principals valors de la flauta dolça és el seu caràcter universal, ja que és l'instrument musical més antic que es conserva: al llarg de la història ha estat present en totes les cultures i s'ha perfeccionat constantment, aprofitant els guanys del passat $i$ introduint millores per adaptar-se a les noves demandes de cada època o lloc. Malgrat les múltiples i variades denominacions donades a l'instrument, podem establir com a originals les de flauta dolça (posteriorment flauta de bec) i Ricordo, en anglès), àmpliament documentades i relacionades amb la producció del so, el seu timbre, la forma de l'instrument i la seva capacitat evocadora. Com indica el seu nom, el seu so suau (arriba a $p p$ de 30 $\mathrm{dB}$ ) és apropiat per a espais tancats i no gaire grans, com a instrument de cambra, condició que l'apartà dels escenaris simfònics occidentals durant el s. XIX i que -si no s'implanta un altre model de flauta dolça- seguirà essent una de les seves principals limitacions, malgrat les alternatives per dissimular el seu escàs marge dinàmic, com l'ús de diferents tipus de vibrato (de laringe, amb els dits o diafragma), o l'ús de mitjans electroacústics d'amplificació. La riquesa dinàmica motivada per la varietat d'articulacions, encara que subtil, és un dels seus principals valors.

El timbre de la flauta dolça i la seva forma han motivat que s'hagi utilitzat com a símbol d'allò sobrenatural en tot tipus de cultes, representacions pictòriques i escenes musicals. $\mathrm{Si}$, a més, tenim en compte el caràcter màgic atribuït a certs materials utilitzats en la seva construcció, ens trobem davant d'un instrument amb un alt valor espiritual, apte per a representar ambients nocturns, màgics, celestials o hipnòtics. A l'antiga Grècia simbolitzava el poder de la música (ja que acompanyava Euterpe); també ha representat el món de l'esperit, la intel-ligència, la vida equilibrada, i amb ella es fabricà el primer diapasó de la història. Com a símbol, la seva hermenèutica ambigua planteja atributs oposats: celestial i mundana (acompanyant àngels i dimonis), 


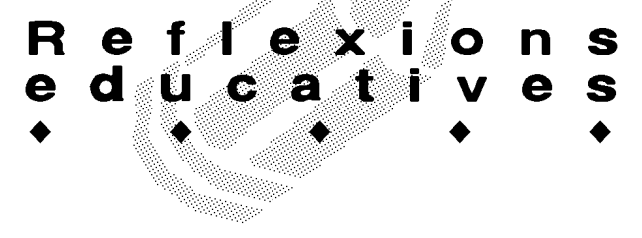

femenina i masculina (per la tesitura o la forma), seriosa o alegre (escenes sobrenaturals o del gènere pastoral), etc. La seva analogia amb el cant dels ocells la relaciona amb ambients de pastors, amb la imitació de la natura i amb la representació dels àngels o estats superiors de l'ésser.

\section{Història}

Un breu repàs a la història de la flauta dolça mostra com les preferències en les seves dimensions han variat: mentre que la soprano fou probablement la preferida a l'Edat Mitjana, al Renaixement es limità a octavar i ornamentar melodies, i fou la tenor la preferida fins al Barroc. En aquesta època la contralt passà a ser la favorita fins als nostres dies. Respecte al seu ús, cal assenyalar que a l'Edat Mitjana -amb una presència massiva a la Cort de Catalunya-Aragó i a Itàlia- i al Renaixement, la flauta dolça acompanyava el cant en
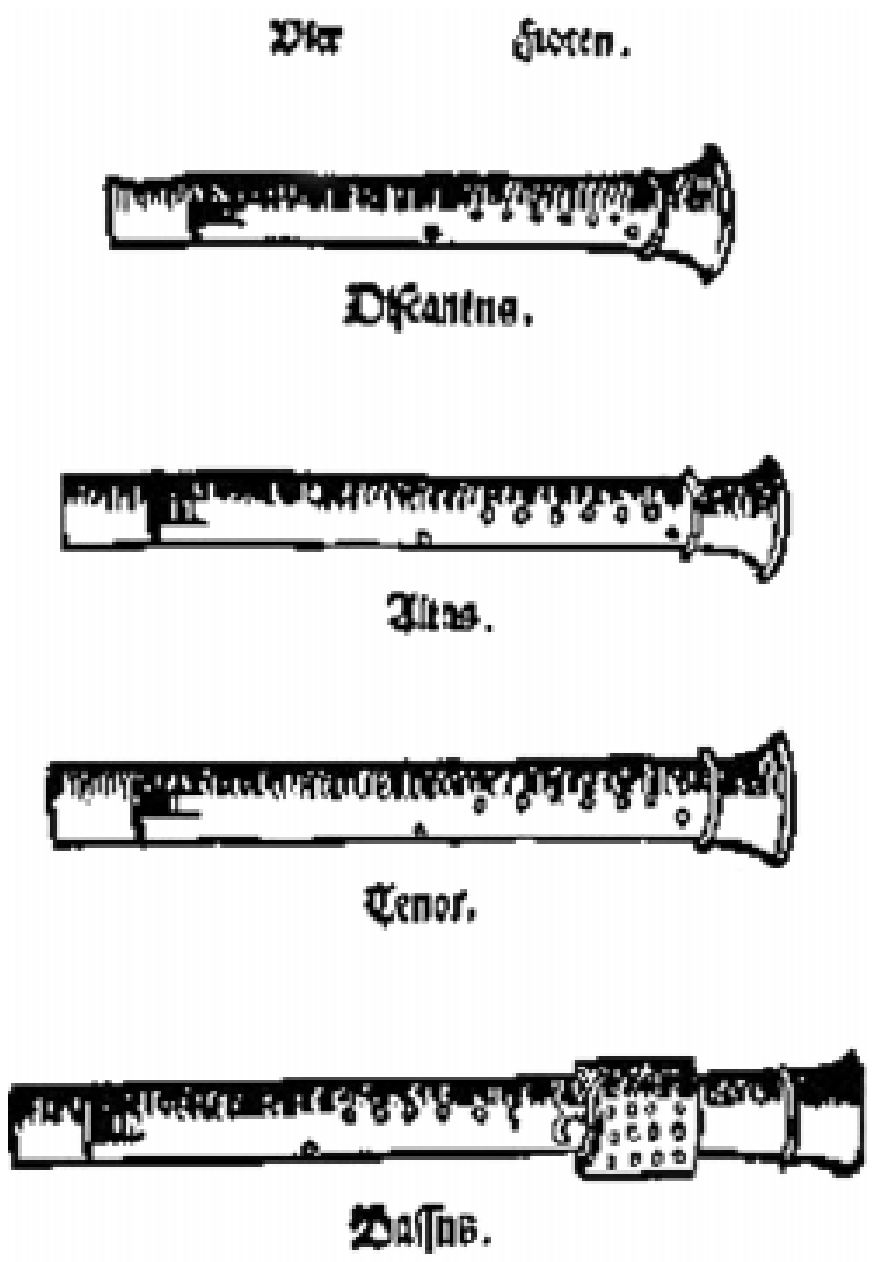

Quartet de bec, al tractat Musica Instrumentalis Deudsch, de Martinus Agricola (Würtemberg, 1528 i 1545). conjunts instrumentals i en la música de dansa, especialment en espais tancats. Al Barroc i al s. XX, la flauta dolça ha gaudit d'un paper rellevant en els gèneres instrumentals cultes de música de cambra. Quant als models, els estils musicals europeus i l'evolució en les tècniques artesanals de construcció han influït en els seus canvis morfològics: fins al s. XVII es fabricaren d'una sola peça, fet que dificultava l'afinació de conjunt; així mateix, fins a aquest moment, era possible intercanviar l'ordre de les mans per l'existència d'un doble forat al peu (un a cada costat, tapant amb cera el que no s'utilitzava). Durant el s. XVI, la flauta dolça aconseguí una extensió d'una 8a, més una 6a (els models Ganassi afegien 7 notes agudes més).

A partir del s. XVII, la secció interior canvià la forma cilíndrica a cònica invertida, aconseguint una eficaç afinació cromàtica, ampliant la seva extensió, i així es convertí en l'instrument de vent preferit com a solista en els conjunts de cambra. Els exemplars de flauta dolça conservats, així com les tabulatures dels tractats històrics, revelen que abans del s. XX mai no ha existit una digitació estandaritzada per a l'instrument, malgrat les nombroses coincidències entre elles. Al s. XX s'agafaren com a models per a la reconstrucció de la flauta dolça la digitació barroca anglesa (normalment anomenada només barroca) i la digitació alemanya, agafada, segons sembla, d'un exemplar barroc alemany; aquesta última digitació ha provocat controvèrsies i debats als ambients didàctico-musicals durant dècades. Malgrat les innovacions proposades a finals del s. XVIII, durant el s. XIX la flauta dolça va desaparèixer de l'escena musical culta fins a la seva restauració a principis del s. $X X$. Les flautes dolces escollides per a fer-ho foren còpies en diapasó modern de models del Barroc amb digitació anglesa, encara que més tard s'estengué també la digitació alemanya. La popularització de la flauta dolça durant el s. XX ha estat ocasionada, en part, pel seu ús escolar i amateur, i per la seva fabricació en sèrie, que n'abaratí el preu, de manera que ha arribat a ser l'instrument musical más fabricat i venut al món. Durant la dècada de 1970, les flautes dolces amb digitació alemanya resultaven una mica més econòmiques que les barroques (al voltant d'un 10\%), per la qual cosa fins als anys 80 fou la més generalitzada a les escoles. Posteriorment ambdues digitacions igualaren preus, especialment en plàstic, cosa que ha facilitat la implantació de la barroca anglesa.

\section{La flauta dolça a l'ensenyament}

La flauta dolça escollida per a l'escola ha estat la soprano, tant en digitació barroca anglesa com alemanya, preferentment amb dobles forats al peu, aconsellant-se 


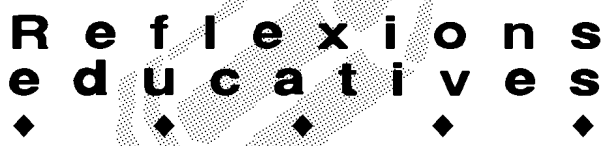

unificar al màxim els models a l'aula. A un nivell més avançat, s'acostuma a adoptar la digitació barroca (si no s'ha fet inicialment) per aconseguir afinar alguns sons com el fa \#, fa' \# i sol' \#(en soprano). A vegades s'arriba a introduir la flauta dolça en fa (normalment la contralt), sense transportar la peça o mitjançant petits trucs per facilitar la seva execució (dobles notes transportades, o ús de la clau de do en 2a línia amb una alteració de diferència). Malgrat la similitud de digitacions entre la tenor i la soprano, aquella no sol utilitzar-se a l'escola per la major grandària de mans requerit, flux aeri i preu, encara que alguns autors l'incloguin en llurs propostes de conjunt instrumental a la secundària.

Quant a l'ensenyament de la flauta dolça, cal destacar que els primers tractats que es conserven es remunten al s. XVI (el tractat més antic que es conserva dedicat a l'ensenyament d'un instrument és de flauta dolça), i fins al s. XX han estat destinats a amateurs. Juntament amb taules de digitacions, s'hi proposaven solucions tècniques als requeriments estilístics de cada moment (ornamentacions, cadències, articulacions, digitacions auxiliars, vibrato, etc.), a més d'un repertori original o adaptat d'exercicis i peces. Als tractats del s. XX podem apreciar diverses tendències en l'ús de la flauta dolça: com a instrument virtuós, com a instrument amateur i d'iniciació a la música. En el primer cas, s'inclouen els estils compositius més rellevants del $\mathrm{s}$. $\mathrm{XX}$, així com recursos tècnics i expressius (multifònics, glissandi, vibratos, frullatti, percussió de l'instrument, cant en flauta, etc.). En el segon cas, trobem una breu introducció a la tècnica elemental (col·locació de dits, mans i boca; taules de digitacions amb lletres, noms o gràfics dels forats tapats en negre, etc.); un ordre progressiu de sons (començant per la mà esquerra i arribant progressivament als greus, les alteracions i els aguts); un tipus bàsic d'articulació (atac simple); un repertori que combini exercicis rítmico-melòdics amb melodies populars (especialment entre 1975 i 1990) o d'autor (fins a 1975 posen l'èmfasi en la música antiga, i després de 1990 en la música moderna) per a una o diverses veus, cànons 0 amb acompanyament de percussions, piano o guitarra. Alguns mètodes faciliten la lectura de notes mitjançant recursos que redueixen el nombre de conceptes a què atendre (com el Flautigrama rítmic, la Fononímia o la Mà-pentagrama); i a la dècada de 1990 alguns autors inclouen suports audiovisuals (playbacks) i informàtics (software).

Amb la inclusió de l'educació musical a l'educació obligatòria, l'ensenyament de la flauta dolça s'implantà gradualment als centres educatius a partir del 2 n quart del s. XX, encara que la seva situació a cada país s'hagi vist condicionada pels recursos econòmics, lleis educatives i la formació i motivació del professorat. Els principals factors que l'afavoriren foren: la proposta d'incloure l'experiència artística a l'educació (ONU, Drets del Nen); les recomanacions de la UNESCO (a través de l'ISME) d'utilizar l'instrument per participar activament com a oients, intèrprets i improvisadors; l'ús de la flauta dolça per alguns autors de "mètodes actius" d'educació musical (com J. Dalcroze, C. Orff o Z. Kodály); l'èxit aconseguit en les experiències pioneres d'algunes es-

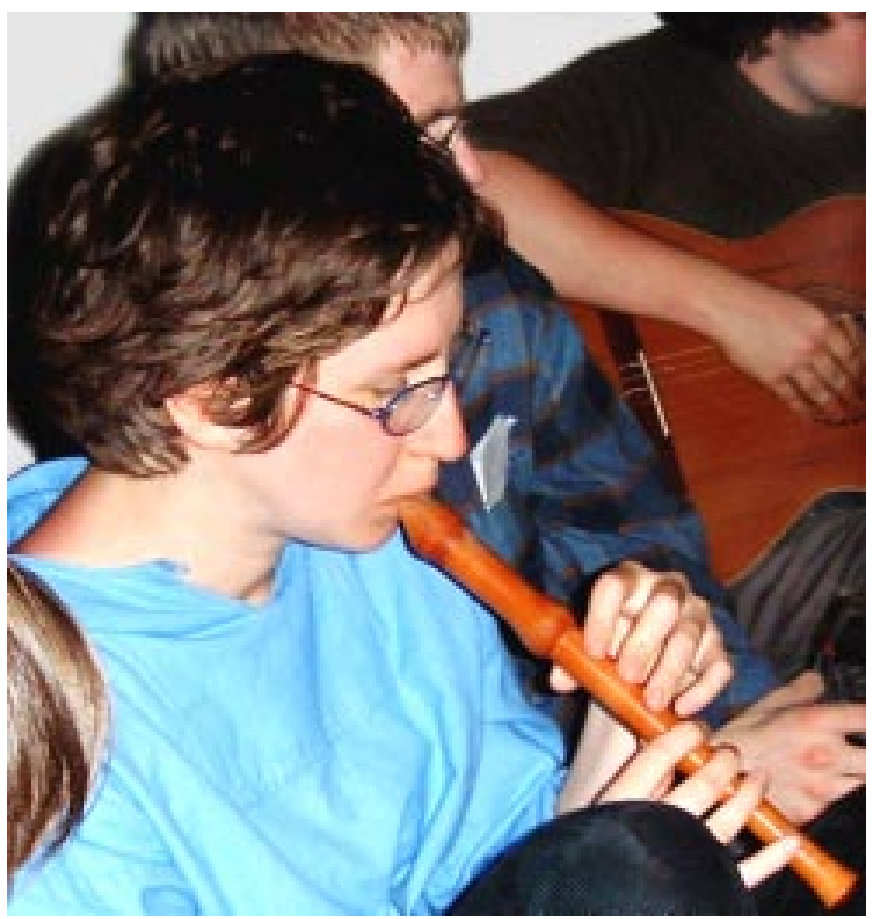

coles angleses, franceses i suïses des de 1935; i alguns antecedents de l'ús d'instruments de vent a l'educació, com el "tonete" a Argentina o el flabiol a Catalunya.

Entre els principals arguments a favor de l'ús escolar, en destaquen: la rapidesa del seu aprenentatge tècnic en la fase inicial; el seu baix preu; l'eficàcia en la pràctica de la lectura musical amb instrument; les possibilitats com a substitut de la veu a l'edat de la muda; les possibilitats polifòniques en el treball col-lectiu; les possibilitats d'ús per alumnat amb diferents nivells de coneixements i fins i tot amb algunes discapacitats (com tenir una sola mà); Ilur funció propedèutica; la incidència en el control de l'aire i la coordinació buco-manual; la motivació que produeix als infants; l'ampli repertori original i/o adaptat, amb moltes publicacions a l'abast; el seu caràcter d'objecte transportable, que permet adaptar-se a diferents circumstàncies de la vida dels escolars, etc.

No obstant això, també hem de citar alguns inconvenients del seu ús: les limitacions dinàmiques; la poca presència en el món concertístic; la dificultat per executar 


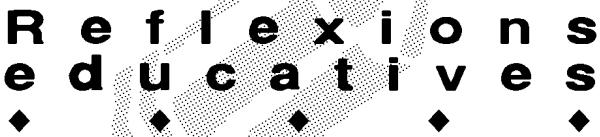

les notes greus; la mala qualitat sonora d'alguns models; les dificultats per acompanyar les sessions de dansa o de rítmica; el mal exemple que donen alguns mestres al tocar-la a causa de llur escassa formació; i la manca de tradició com a instrument folklòric.

Tenint en compte els coneixements actuals sobre la maduració psico-biològica dels escolars, podem atribuir al prototip d'estudiant de flauta dolça les següents característiques:

- Edat:major de 9 anys (pel desenvolupament psicomotor, la morfologia de la mà, l'augment en un $70 \%$ de la capacitat vital aèria respecte als 6 anys d'edat, la semblança amb la veu aguda i l'inici de l'etapa piagetiana de les operacions concretes).

- Sexe: indistint (a aquesta edat ambdós sexes coincideixen en capacitat aèria, i encara que en lectura musical les nenes acostumen a estar més avançades, els nens es mostren millors improvi- sadors i creadors).

- Nivell cognoscitiu: divers (trobem nivells molt variats).

- Personalitat: bon equilibri interpersonal i adaptació a les exigències socials, identificant-se amb l'ambient familiar i apreciant els propis valors.

A Espanya la introducció de la flauta dolça a l'escola no es dugué a terme fins a l'EGB, als Programes Renovats per a Cicle Superior (1981), encara que la seva implantació depengué de la capacitació específica del professorat, ja que no es contemplava la dotació d'especialistes de música. S’incloïen la interpretació de cançons populars amb l'instrument, el seu reconeixement auditiu, la imitació, creació, exploració i improvisació rítmico-melòdica amb flauta dolça, i l'ús per part del professor d'exercicis de llenguatge musical. A Catalunya, després dels traspassos de competències educatives (1980), només arribaren a publicar-se els programes de

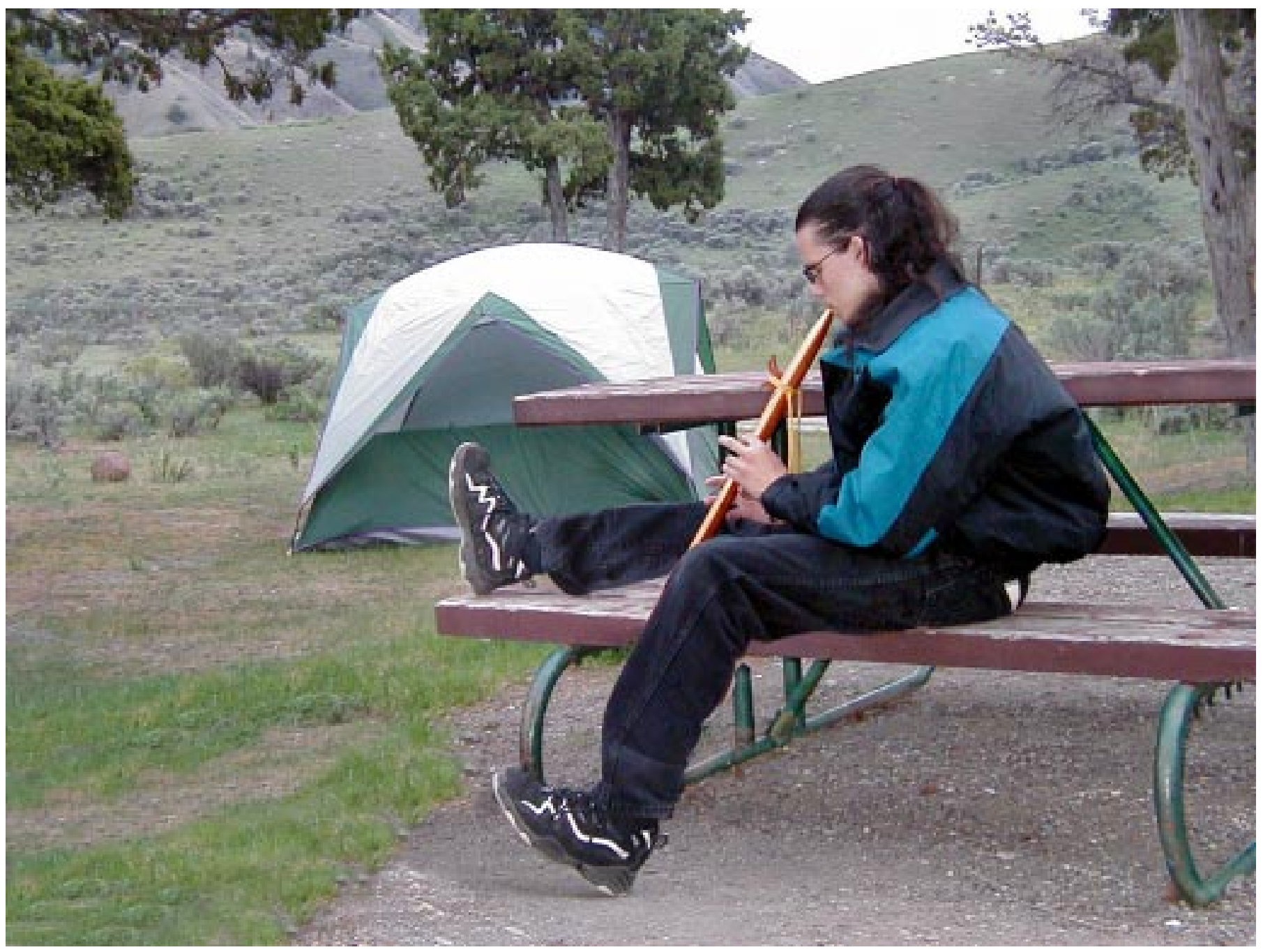




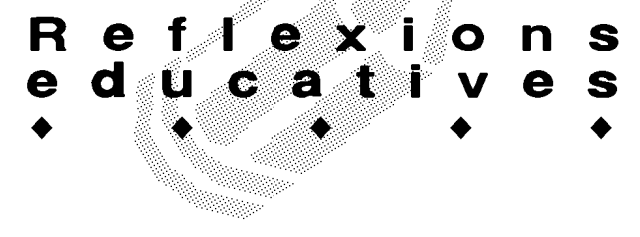

cicle inicial i mitjà d'EGB, on la flauta dolça era contemplada com un instrument a observar i manipular. EI BUP (1975) considerà la música com una matèria obligatòria impartida per professorat titulat, centrada fonamentalment en la història de la música, amb la possibilitat d'abordar la interpretació musical mitjançant flauta dolça o d'altres instruments, encara que no de forma obligatòria. A la formació professional no figurà cap assignatura de música, exceptuant l'especialitat de puericultura (FP de $2 \mathrm{n}$ grau), on es contemplaven activitats musicals, que podien incloure flauta dolça, encara que el professorat no en fos especialista. Als ensenyaments artístics (conservatoris), la flauta dolça no aparegué en el llistat inicial d'instruments del pla 1966, sinó que s'inclogué a partir de 1975 per un "error administratiu" del Conservatori Superior Municipal de Música de Barcelona. El seu estudi, com el de la resta d'instruments de vent, constava de 8 cursos, que s'iniciaven amb la soprano i es complementaven més tard amb la contralt.

Amb l'aplicació de la LOGSE (1990) arriben els especialistes de música a la primària, i s'inclou la música dins de l'àrea d'activitats artístiques. Al territori MEC, el cant i l'expressió vocal i instrumental són contemplats al $4 t$ bloc de continguts, i encara que no s'expliciti de forma obligatòria l'ús de la flauta dolça (no s'exigeix el seu coneixement als aspirants a mestres de música a primària), sí que apareix als exemples de propostes curriculars del Ministeri i a molts llibres de text. A Catalunya l'ús de la flauta dolça a primària no és obligatori, encara que sigui qualificat per les instàncies educatives d'“estimulant i gratificador si es poden assegurar unes condicions de treball adequades" i es proposi la interpretació de petites composicions instrumentals. A l'ESO la música és una assignatura obligatòria, que inclou el bloc de contingut Expressió instrumental, on es poden trobar propostes de flauta dolça. No s'explicita de forma obligatòria (tampoc no s'exigeix el seu coneixement als aspirants a professors de música de secundària), però la majoria dels llibres de text la inclouen. A Catalunya la flauta dolça es contempla dins dels Crédits variables tipificats, amb una extensa i completa programació de tipus teòrico-pràctic. Els ensenyaments artístics regulats per la LOGSE inclouen la flauta dolça al llarg dels tres graus proposats, amb uns programes més complets que els del pla 66.

A l'ensenyament universitari la flauta dolça s'introduí al pla 1967 de formació de professorat ("interpretació de petites composicions mitjançant flauta dolça"), continuant al pla 1971 de professorat d'EGB ("coneixement teòricopràctic de la flauta dolça"). El 1985 s'organitzaren postgraus que pretenien formar musicalment mestres en exercici, contemplant en els seus programes la matèria flauta dolça, fins que al pla 1992 la titulació de Mestre en Educació Musicalassegurà una especialitat musical per als mestres. Aquesta titulació s'imparteix a 6 universitats de Catalunya (UB, UAB, URL, URV, UDG, i UDL). i totes elles (a excepció de la UDL) inclouen la flauta dolça en els seus programes. En ells es presenten continguts (coneixement i tècnica bàsica de l'instrument, repertori musical, habilitats musicals aplicades a l'instrument i el seu ús escolar) i avaluació (tipus i criteris); a més, la majoria d'universitats proposa objectius (referits a l'execució invididual i col-lectiva amb l'instrument, i referits al seu ús didàctic escolar) i metodologia (tècniques de treball i agrupaments d'alumnat). La gran majoria dels professors universitaris de flauta dolça estan a favor del seu ús perquè és un instrument escolar, té unes dimensions reduïdes, caràcter individual i col-lectiu, baix preu i senzillesa inicial en el seu aprenentatge, malgrat que es consideri poc adequat per a alguns estils musicals, no sigui polifònic i resulti difícil d'afinar.

La situació de la flauta dolça al nostre sistema educatiu ens permet ser optimistes respecte al seu futur al s. XXI. Sense excloure l'estudi d'altres instruments, considerem que la flauta dolça té prou capacitat per a formar i educar l'alumnat de primària, secundària i de la titulació de Mestre en Educació Musical. L'educació del futur plantejarà nous reptes, com per exemple, acomodar l'ús de l'instrument a noves situacions derivades dels entorns multimedia, o vetllar per la qualitat de l'ensenyament presencial (l'únic que garanteix una tradició completa i eficaç del coneixement). L'èxit en aquesta tasca és responsabilitat de tots els qui compartim l'amor per aquest instrument. El seu ensenyament i difusió poden ser també un motor per impulsar la societat en què vivim, que desitjaríem més musical, justa i humana.

\section{Bibliografia consultada}

GUSTEMS, J. La flauta dulce en los estudios universitarios de "Mestre en Educació Musical", a Catalunya: revisión y adecuación de contenidos. Barcelona. 2004. Universitat de Barcelona (Tesi doctoral). http://www.tdx.cesca.es/TDX-0716104104533.

\section{Webs d'interès}

http://www.terra.es/personal/joanvips/debec.htm http://www.members.iinet.net.au/-nickl/torture.html http://www.theshops.co.uk/childsplay/tour.htm http://www.music.indiana.edu/music_resources http://www.talentz.com/Musiceducation/index.mv http://www.orpheusmusic.com.au/compguides.html 